\title{
NIETZSCHE: a boa forma de retribuir ao mestre
}

\author{
NIETZSCHE: \\ a good way to be thankful to his master
}

\begin{abstract}
Antonio Edmilson Paschoal
Doutor em Filosofia, Unicamp, Campinas, SP. Professor do Programa de Pós-Graduação em Filosofia da PUCPR, Curitiba, PR - Brasil, e-mail: antonio.paschoal@ puc.pr.br
\end{abstract}

\section{Resumo}

Abordaremos neste artigo certos aspectos do pensamento de Nietzsche, explicitados em alguns textos da época em que foi professor de Filologia Clássica na Universidade de Basel, com o objetivo de ressaltar a distância pontuada por ele em relação a seu mestre - Arthur Schopenhauer - já naquele período. Essa distância bem como uma discrepância de intenções entre ambos faz com que o jovem Nietzsche retribua bem ao seu mestre na medida em que não permanece "apenas discípulo".

Palavras-chave: Schopenhauer; Nietzsche; Vontade; Representação; Razão; Intuição.

\section{Abstract}

In this article we intend to analyze some aspects of Nietzsche's thought, which was elaborated in some texts during the time he was a classical philology professor at Basel University. Thus, we aim at emphasizing the distance that, already in that period, he had deepened with regard to his master - Arthur Schopenhauer. This distance, 
together with a discrepancy between both thinkers, caused that Nietzsche fairly reciprocated to his master and, consequently, did not remain a "mere disciple"

Keywords: Schopenhauer; Nietzsche; Will; Representation; Reason; Insight.

"Retribui-se mal um mestre, quando se permanece sempre e somente discípulo"

Assim falou Zaratustra

\section{Apresentação}

A busca de Nietzsche por um mestre parece ter chegado a um termo em 1865, quando ele muda para Leipzig e ali, num velho antiquário, encontra a obra $O$ mundo como vontade e representação, de Arthur Schopenhauer. De fato, há um consenso entre os comentadores da filosofia de Nietzsche quanto à forte influência exercida por Schopenhauer sobre seus primeiros escritos. Essa influência pode ser apontada, a título de exemplo, na transposição feita por Nietzsche da relação entre vontade e representação para a dualidade Apolo e Dionísio (HAAR, 1993) e também na sua concepção da "música como expressão imediata e universal da vontade entendida não como vontade individual, mas como essência do mundo[...]" (MACHADO, 2005, p. 8).

Para além dessa clara influência, no entanto, pretendemos mostrar que o emprego que o jovem professor de Filologia Clássica faz "de fórmulas schopenhauerianas..." (NT, prefácio de 1886,5$)^{1}$ não o impede de manter uma

1 Para as obras de Nietzsche aqui citadas utilizaremos as seguintes siglas: O nascimento da Tragédia (NT); A filosofia na época trágica dos gregos (FTG); Considerações Extemporâneas I: David Strauss o confessor e o escritor (CE I); Considerações Extemporâneas II: Schopenhauer Educador (CE III); Ecce Homo (EH); Fragmentos póstumos 7 (KSA 7). No parêntese, após estas siglas, segue-se a indicação das partes conforme numeração feita pelo autor e no caso da KSA, o número da página. 
salutar distância em relação ao seu "mestre". Segundo a tese que ora defendemos, Nietzsche se serve da filosofia de Schopenhauer para realizar propósitos bem diferentes daqueles pretendidos pelo filósofo de Frankfurt. Assim, caso se considere, por exemplo, a crítica às pretensões da razão lógica, elaborada em seus primeiros escritos, deve-se observar que ela, embora se alie ao movimento de despotencialização da razão, iniciado por Schelling e Schopenhauer, possui contornos exclusivos e peculiaridades próprias.

Como hipótese inicial de trabalho, assumiremos que aquelas peculiaridades do pensamento de Nietzsche, em alguns casos, tornam-se mais explícitas ao se passar da obra publicada para os textos que ele não encaminha para publicação. Assumiremos também que a proximidade com Schopenhauer nas obras levadas a público nesse período, embora não seja incondicional, ocorre, em certas passagens, em função de um posicionamento adotado no embate de Nietzsche com a cultura de sua época, no qual Schopenhauer e Wagner são aliados importantes. Isto faz com que Nietzsche apresente um cuidado maior em mostrar-se coerente com o pensamento de Schopenhauer nas obras publicadas do que nos textos que permaneceram inéditos naquele período.

A título de exemplo, pretendemos apontar, das obras levadas a público, alguns pontos da terceira e da primeira das suas Considerações extemporâneas e também de $O$ nascimento da tragédia; e dentre os textos não encaminhados pelo filósofo para publicação, alguns pontos de A filosofia na época trágica dos gregos e o conhecido fragmento 12 [1], de 1871, escrito inicialmente como parte de $O$ nascimento da tragédia, depois retirado, remodelado e, por fim, mantido apenas no conjunto de suas anotações pessoais. Nestes últimos, conforme veremos, o cuidado inicial de Nietzsche em manterse coerente com suas opções naquele conflito com a cultura de sua época não se apresenta como uma exigência de primeira ordem.

Ressalvamos, contudo, que essa hipótese não se confirma na forma de uma contraposição simples entre textos exotéricos e esotéricos. Pois, por um lado, tendo em vista aqueles levados a público, quando Nietzsche parece mais alinhado com o pensamento de Schopenhauer, não se pode ignorar, conforme veremos, que em vários momentos ele não acompanha seu mestre. $\mathrm{E}$, por outro lado, tendo em vista os textos não publicados, não se pode afirmar simplesmente que Nietzsche tenha a intenção de promover um rompimento com Schopenhauer, uma de suas principais fontes no período. Ademais, também não se pode perder de vista que ele, o mais oculto dos filósofos, muda a função de personagens e conceitos em diferentes textos. A cada momento, a cada nova construção argumentativa, eles são tomados como fios utilizados para tecer 
novas teias. São, portanto, instrumentos e não conceitos ou posições fixas que, uma vez explicitados, exigiriam a fidelidade do filósofo.

\section{Alguns pontos de aproximação de Nietzsche com Schopenhauer nas obras publicadas}

Na Terceira Consideração Extemporânea: Schopenhauer como educador, Nietzsche apresenta seu mestre como um "homem vigoroso e inteiro no sofrer e no desejar e não apenas uma sacolejante máquina de pensar e calcular" (CE, III, 3). O filósofo de Frankfurt é tido por Nietzsche como o oposto à sobrevalorização da razão lógica que predominou no mundo ocidental e à tendência à extirpação e erradicação da cultura na Alemanha do século XIX. Sendo assim, Schopenhauer é um extemporâneo na medida em que escapa às enfermidades de seu tempo. Alguém que Nietzsche associa a Empédocles, a melhor expressão, segundo ele, ${ }^{2}$ do vigoroso e efusivo prazer de viver da cultura grega, um homem criador que não coloca a vida em julgamento, mas a legitima por sua própria existência.

Na Primeira extemporânea, o jovem professor de filologia se posiciona igualmente a favor de Schopenhauer - e de Wagner -, apontando-o como expressão do espírito alemão, ao mesmo tempo em que ataca David Strauss, identificando-o como o representante de uma tendência à extirpação daquele espírito. Tendência que se verifica no júbilo produzido pela vitória dos alemães sobre os franceses na guerra franco-prussiana, na crença no Reich instaurado por Bismarck em 1871 e no que Nietzsche chama de "filisteísmo da cultura": (CE I, 2) a atitude dos homens instruídos de sua época, em especial do burguês culto, crente no progresso da sociedade e na bondade humana, que tomava a si como ponto de chegada de toda cultura e a arte apenas como objeto de distração e entretenimento. Nesse contexto, de um otimismo exacerbado, a crítica de Nietzsche se apresenta como uma opção pelo pessimismo - por Schopenhauer. Assim, se para David Strauss toda filosofia verdadeira é otimista e todo pessimismo não teria direito à existência, pois nega a si mesmo e ao mundo (CE I, 6), para Nietzsche, o otimismo, especialmente em relação à razão

2 Em um fragmento do período entre o inverno de 1869 e a primavera de 1870, (KSA 7, p. 83) Nietzsche apresenta Empédocles como o grego ideal e perfeito e mais adiante, num fragmento escrito entre setembro de 1870 e janeiro de 1871 , (KSA 7, p. 118) como o homem trágico puro. O que permite entender a importância conferida por Nietzsche a Schopenhauer ao associá-lo a Empédocles na Terceira extemporânea. 
e às suas explicações para os enigmas do mundo e da existência, é característico de períodos de decadência, dissolução e fraqueza, nos quais não se consegue olhar de frente o problema da dor e do sofrimento.

Desconsiderado como sintoma de um problema fisiológico, de um cansaço diante da vida, aquele otimismo da razão nem teria motivos para existir, pois um exame do intelecto revelaria que ele não pode dar conta de desvendar os enigmas do mundo. Segundo Nietzsche - acompanhado em grande parte seu mestre - os instrumentos do intelecto que são o conhecimento lógico-racional, a linguagem e a palavra, servem apenas para representar o mundo, para traduzir aquilo que se adquire por intuição (Anschauung) e não para atingir a realidade em sua essência última.

A superioridade do conhecimento intuitivo em relação ao conhecimento abstrato é manifestada por Nietzsche desde os primeiros parágrafos de $O$ nascimento da tragédia, quando ele destaca o papel da intuição para a compreensão da contraposição entre o apolíneo e o dionisíaco entre os gregos: Apolo é o princípio de individuação, enquanto Dionísio, o Uno-primordial; e também: Apolo é a representação, o sonho que nos permite desfrutar a vida, enquanto Dionísio é a embriaguez que possibilita dissolver o princípio de individuação e lançar um olhar para aquela unidade de tudo o que existe.

Em $O$ nascimento da tragédia, a oposição a este tipo de sabedoria intuitiva é exercida por Sócrates, o qual a desqualifica como ilusão e insensatez, renunciando a ela e colocando em seu lugar o conhecimento abstrato produzido por uma razão que supostamente oferece a segurança para ele poder afirmar: "só o sabedor é virtuoso" e mais, que "tudo deve ser consciente para ser bom". (NT, 12) Segundo Nietzsche, porém, o posicionamento de Sócrates em relação ao conhecimento termina por produzir uma monstruosidade: ao invés de tomar a intuição como fonte de inspiração e a consciência como o esforço por representar aquilo que se adquire intuitivamente, ele apresenta um demônio (uma inspiração mística, uma intuição) como crítica do conhecimento e confere à consciência o que justamente ela não possui: a capacidade de criação.

Nesse mesmo caminho, segundo Nietzsche, encontra-se Platão "empenhado em ultrapassar a realidade" (NT, 14) por meio da razão e proclamando "o otimismo existente na essência da dialética, que celebra em cada conclusão a sua festa de júbilo e só consegue respirar na fria claridade da consciência." (NT, 14). Para Nietzsche, essa dialética otimista recusa a embriaguez dionisíaca, contrapondo a ela "aquela inabalável fé de que o pensar, pelo fio condutor da causalidade, atinge até os abismos mais profundos do ser e que o pensar está em condições, não só de conhecê-lo, mas inclusive corrigí-lo." (NT, 15). Um conhecimento que promete desvendar os mistérios do mundo e revelá-lo seguro e confiável. 
Em contraposição ao otimismo de Sócrates e Platão diante da existência, Nietzsche, inspirado em Schopenhauer, recorre ao olhar trágico para mostrar uma existência que inclui o sofrimento e que está fadada à destruição da individualidade e à necessária reabsorção no Uno-primordial. O mesmo olhar trágico que revela a ele um conhecimento diferente do lógico-racional. Um conhecimento que só pode ocorrer por meio de um "sentimento místico de unidade" (NT, 2), de uma premonição e não por meio do fio condutor da causalidade, como acreditavam Sócrates e Platão.

\section{O pessimismo versus um "pessimismo da fortitude"}

O fato de mostrar-se "inspirado em Schopenhauer", contudo, não significa que Nietzsche se torne um seguidor de Schopenhauer. Ao contrário, conforme veremos, existem mais dessemelhanças do que semelhanças entre o pessimismo de Schopenhauer e a crítica de Nietzsche ao otimismo da razão e às suas causas. A Nietzsche, por exemplo, não interessa tanto uma avaliação da vida humana como um pêndulo entre a dor e o tédio, mas o sofrimento como um aspecto inerente ao fenômeno da vida, bem como a capacidade do homem de se situar diante da dor e do sofrimento sem com isto colocar a própria vida em julgamento. Ademais, para Nietzsche, não se verifica um saldo negativo no balanço entre felicidade e sofrimento, em cujas bases se poderia concluir que a vida não vale a pena ser vivida.

Enquanto Schopenhauer procura eliminar o sofrimento por meio da negação da vontade, para Nietzsche o sofrimento não deve ser negado, mas justificado pela aparência, pela criação artística, "pois só comofenômeno estético podem a existência e o mundo justificar-se eternamente" (NT, 5). Em outras palavras, tanto o indivíduo quanto "o Uno-primordial, enquanto o eternopadecente e pleno de contradição necessitam, para a sua constante redenção, também da visão extasiante, da aparência prazerosa" (NT, 4).

Outra diferença entre ambos vem à tona com a pergunta acerca da finalidade pela qual, segundo Nietzsche, o grego manifesta aquela disposição para o sofrimento, para olhar de frente o caráter trágico da existência. E a resposta: "trata-se de uma fórmula de afirmação suprema nascida da abundância, da superabundância, um dizer sim sem reservas[...]". (EH, Nascimento da tragédia, 2). Para Nietzsche, do reconhecimento do sofrimento como parte integrante da vida pelos gregos não decorre uma negação da vida ou do mundo, porém, um sim sem reservas, numa "fantástica aceitação da vida" (NT, 3) que 
não busca ocultar qualquer aspecto da vida, como fazem os otimistas em relação à dor e ao sofrimento.

Em sua "tentativa de autocrítica", em 1886, Nietzsche descreve essa disposição dos gregos para não desviarem os olhos do sofrimento, bem como a necessária dissolução do indivíduo como uma "boa e severa vontade [...] para o mito trágico, para a imagem de tudo quanto há de terrível, maligno, enigmático, aniquilador e fatídico no fundo da existência" (NT, prefácio de 1886, 4). Segundo ele, somente no tempo de sua dissolução os gregos se tornaram otimistas, superficiais e "ansiosos por lógica e logicização" (NT, prefácio de 1886 , 4). Nesse momento, em 1886, ressalta a principal peculiaridade de seu trabalho de 1872: "aqui se anuncia, quiçá pela primeira vez, um pessimismo além do bem e do mal." (NT, prefácio de 1886, 5). Assim, reafirma que a utilização que fizera das fórmulas de seu mestre e o fato de mostrar-se estrategicamente ligado a ele naquele período, não implica em tornar-se propriamente schopenhaueriano, ao menos não até as suas últimas implicações, como por exemplo, a negação da vida. ${ }^{3}$

Para Nietzsche, a percepção do caráter trágico da existência conduz à afirmação da vida, uma vez que não é sinal de fraqueza, mas de saúde transbordante. É a serena-jovialidade dos gregos que permite a eles colocarem diante de si o sofrimento na sua forma mais crua e suportá-lo sem precisar, para isso, de uma explicação otimista, utilitarista, prática ou racionalista para a existência. Da mesma forma como não precisavam buscar uma explicação para o sofrimento deste mundo em um outro no qual o sofrimento deste seria compensado, como fazem várias religiões. Por fim, não se trata de curvar-se ao destino, de suportar o sofrimento por não haver outra alternativa, como uma forma de resignação, mas de afirmá-lo por prazer. Assim, se é certo que o homem é uma "estirpe miserável e efêmera" constituída de "filhos do acaso e do tormento", em relação à qual Sileno afirma "O melhor de tudo é para ti inteiramente inatingível: não ter nascido, não ser, nada ser. Depois disso, porém, o melhor par ti é logo morrer". É certo também que, conhecendo e sentindo os horrores do existir, e mais, transfigurando este horror por meio dos deuses olímpicos, "até o seu lamento

3 Mais tarde, em sua autobiografia, em 1888, Nietzsche prefere enfatizar a diferença em relação ao antigo mestre afirmando que em $O$ nascimento da tragédia se encontra um "primeiro esclarecimento sobre como os gregos deram conta do pessimismo - com que o superaram...". Assim, diferentemente do que dissera em 1872 e, dadas as proporções, também em 1886, ele conclui que "a tragédia precisamente é a prova do que os gregos não foram pessimistas", e provoca: "Schopenhauer engana-se aqui, como se enganou em tudo". (EH, Nascimento da tragédia, 1). 
[dos gregos] se converte em hino de louvor à vida." E eles podem inverter a proposição de Sileno e afirmar: "a pior de todas as coisas é para eles morrer logo; a segunda pior é simplesmente morrer um dia." (NT, 3).

Como a claridade de uma vela que é "suspensa" pela claridade do sol, a vida particular não é negada na arte, mas encontra nela - especialmente na tragédia - um consolo metafísico. A vida se corporificada no coro satírico, um coro de "seres naturais que vivem, por assim dizer, por trás de toda civilização, e que, a despeito de toda mudança de gerações e das vicissitudes da história dos povos, permanecem perenemente os mesmos". Como se pode observar, a vida como Nietzsche apresenta no sétimo parágrafo de $O$ nascimento da tragédia, não é pensada em termos particulares, mas como um princípio que se mantém apesar de todas as mutações e vicissitudes. A vida, "no fundo de todas as coisas, apesar de toda a mudança das aparências fenomenais, é indestrutivelmente poderosa e cheia de alegria[...]"(NT, 7). Desta forma, Nietzsche está novamente marcando distância em relação a Schopenhauer, pois apresenta a vida e não a vontade como o substrato que permanece sempre, a despeito de todas as vicissitudes da natureza e da história. Acentua esta diferença, o fato de tal substrato - a vida - não ser um princípio a ser negado, uma vez que é justamente ela o consolo metafísico que a arte grega antepõe às propensões destrutivas da história e às crueldades da natureza.

\section{Os limites da palavra "vontade" para dizer o "indizível” no fragmento 12 [1].}

A ideia de um princípio originário, a "única 'eudade' (ichheit) verdadeiramente existente (seiende) e externa, em repouso no fundo das coisas" (NT, 5), o único fundamento metafísico de tudo o que existe, o ser-em-si do qual emana toda representação é designado por Nietzsche nos seus primeiros escritos preferencialmente por meio da expressão "Uno-primordial". Tal ideia, especialmente em algumas passagens de $O$ nascimento da Tragédia, encontra-se associada também à noção de "vontade" de Schopenhauer, sendo que em alguns momentos Nietzsche

4 O termo "vontade" aparece entre aspas quando se trata de uma referência direta ao seu significado no pensamento de Schopenhauer. Pode-se inferir que ao separá-lo de seu próprio texto, Nietzsche já esteja marcando uma distância em relação ao Filósofo de Frankfurt. 
se permite nomeá-la desta forma, comoé o caso, por exemplo, do parágrafo terceiro, ao afirmar: "nos gregos a 'vontade' queria, na transfiguração do gênio e do mundo artístico, contemplar-se a si mesma" (NT, 3).

Contudo, a despeito de tal correlação entre o Uno-primordial e a "vontade", já em seu livro de 1872, Nietzsche procura diferenciá-los quando associa a "vontade" ("tomando-se a palavra no sentido de Schopenhauer") à poesia lírica, considerada "como fulguração imitadora da música em imagens e conceitos". Dessa forma, ele propõe que a música (anterior à lírica e à palavra), não tem sua origem diretamente ligada à "vontade", mas ao Uno-primordial e que, por meio de uma intuição mística, o gênio, "no ato da procriação artística, se funde com o artista primordial do mundo." (NT, 5). Segundo Nietzsche, esta afirmação o afasta de seu mestre, pois, para Schopenhauer "o sujeito da vontade, isto é, o próprio querer, preenche a consciência de quem canta[...]" ( $O$ mundo como vontade e como representação, I, p. 329 - citado por Nietzsche em NT, 5).

Tal interesse em mostrar um distanciamento em relação ao seu mestre é explicitado de forma contundente no fragmento 12[1]. Nele a ideia de uma unidade existente em repouso no fundo de todas as coisas deixa de ser nomeada de forma positiva, inclusive como Uno-primordial, passando a receber uma designação negativa, como faz Anaximandro de Mileto, por meio de expressões como "indecifrável", "indeterminado", "indizível”, "além-de-todaindividuação", etc.. Dessa forma, ele nega a possibilidade de dizer - equivalente a decifrar - o princípio originário, o que o colocaria no campo da individuação, semelhante a outras representações.

"Contra Schopenhauer", ${ }^{5}$ Nietzsche afirma que mesmo a "vontade" não poderia ser a essência de tudo o que existe, uma vez que ela corresponde a uma forma de representação. Segundo ele, no fragmento 12[1], as palavras são apenas símbolos que nos permitem explicar o conteúdo das representações e não possuem qualquer ligação necessária com as coisas e muito menos com a "coisa-em-si". Também o termo "vontade" tem seu solo de origem no plano da representação e não poderia remeter àquilo que está além desse plano. Da mesma forma como a vontade não poderia ser tomado como uma manifestação daquilo que é para nós totalmente indecifrável. D'onde se conclui que uma afirmação que nomeia a essência de todas as coisas como "vontade", só tem valor simbólico no campo da linguagem.

5 De certa forma contra si mesmo também, pois a expressão "Uno-primordial”, embora não indique nada tão próprio à representação como o termo "vontade", também ela é uma designação positiva. Opção que Nietzsche rechaça no fragmento 12[1] quando procura demarcar mais claramente sua distância em relação ao pensamento de Schopenhauer. 
Portanto, ao submeter a "vontade" de Schopenhauer ao mais rigoroso autoexame, ele termina por concluir que ela "nada mais é que a forma mais universal da aparência de algo que para nós permanece completamente indecifrável" (KSA 7, p. 361). E utiliza a expressão "indizível" justamente em oposição à palavra "vontade", que é "dizível" e, por conseguinte, não poderia, a não ser como uma metáfora, corresponder àquilo que se encontra além de toda individuação.

\section{Duas críticas em A filosofia na idade trágica dos gregos}

Em seu livro de 1873, A filosofia na idade trágica dos gregos, obra publicada apenas postumamente, Nietzsche faz uma aproximação entre o "indeterminado" de Anaximandro, entendido como a essência imutável por trás do mundo das coisas determinadas, e a "vontade" de Schopenhauer, entendida igualmente como a essência última de todas as coisas. Tal aproximação parte de dois princípios. Primeiro, do reconhecimento de uma intuição mística ${ }^{6}$ na origem de ambas as proposições e, segundo, da interpretação da "vontade" de Schopenhauer como uma metáfora antropomórfica utilizada pelo filósofo de Frankfurt para explicitar aquela intuição que ele teria encontrado "no alto da atmosfera indiana" (FTG, 4) e aplicado na explicação de toda a existência.

Outra semelhança entre Schopenhauer e Anaximandro, destacada por Nietzsche em seu livro de 1873, é a forma como ambos vêem a culpa na origem do sofrimento inerente ao devir do mundo e à existência do homem. Para Anaximandro o devir é "uma emancipação criminosa do ser eterno, uma iniqüidade que tem de ser expiada com a ruína," (FTG, 4) enquanto para Schopenhauer o homem é "um ser que nem sequer deveria existir, mas que expia a sua existência por multiformes sofrimentos e pela morte" (Parerga e paralipomena, livro II, cap. 12. Suplemento à doutrina sobre a dor do mundo, apêndice - citado por Nietzsche em FTG, 4). Para Nietzsche, tal proposição acerca do devir significa, em Anaximandro, um importante deslocamento da preocupação com o princípio originário do campo da física para o da moral, a

6 Como fizera em $O$ nascimento da tragédia, no início de A filosofia na idade trágica dos gregos, Nietzsche (1995) lança sua tese de que é a intuição mística que impele os filósofos a apresentarem postulados metafísicos. É uma intuição dessa ordem que permite, por exemplo, a Tales afirmar a unidade do que existe por meio da metáfora da "água", da mesma forma que permite a Anaximandro postular sua tese sobre o "indefinido". Em ambos, permanece a idéia de um "ser em si" do qual provém a "torrente sempre renovada do devir" (FTG, 4). 
partir da pergunta pelo valor da existência. Sob este mesmo aspecto também na filosofia de Schopenhauer se destaca o fato de apontar a "vontade" como a explicação última para o sofrimento no mundo, para a maldição do vir-a-ser. O problema, em ambos os filósofos, será a resposta apresentada justamente à pergunta pelo valor da existência, a qual termina por depreciá-la, pois aponta a ruína na gênese do que existe e a expiação como sua meta.

Nesses termos, a despeito da solução apresentada para o problema da "vontade" de Schopenhauer (tomando-a como uma metáfora para exteriorizar uma intuição mística), Nietzsche segue avesso às conclusões de seu mestre. E isto se revela quando ele, após aproximar Schopenhauer de Anaximandro, mostra uma grande simpatia para com Heráclito de Éfeso, que não toma o mundo como dualidade, mas considera o vir-a-ser como a única realidade. Segundo Nietzsche, enquanto Anaximandro admite "um domínio das qualidades definidas e um domínio da indefinição indefinível" (FTG, 5), Heráclito nega tanto a divisão que opõe dois mundos diferentes, um físico e outro metafísico, quanto o ser em geral "pois o único mundo que ele conservou [...] nada mostra de aparente, nada de indestrutível, nenhum baluarte no seu fluxo" (FTG, 5). Além disso, na concepção de Heráclito, o devir assim como ao sofrimento que lhe é inerente, não são tomados como uma maldição, castigo ou pagamento por injustiças. Ao "contemplar o devir", ele vê apenas legalidades e não a punição ou o suplício dos condenados. (FTG, 5).

Independentemente da posição extrema de Heráclito e da afeição que Nietzsche demonstra por ela, é importante destacar que ele apresenta duas críticas. A primeira que designamos como a sua crítica às pretensões da razão e que não se aplica ao seu mestre ou a Anaximandro, pois, segundo ele, ambos partem de uma intuição mística para formular suas proposições acerca do mundo e, no caso de Schopenhauer, o termo "vontade" seria tomado como uma metáfora para aquilo que afirmativamente nem poderia ser dito. A segunda crítica, referente à interpretação do sofrimento como um castigo, é direcionada contra seu mestre, em relação ao qual ele procura marcar uma diferença neste ponto ao aproximar-se de Heráclito, para quem o devir é inocente.

Tendo em vista essas duas críticas, pode-se retomar o texto de $A$ filosofia na idade trágica dos gregos e o alcance da crítica de Nietzsche a Parmênides e ao seu postulado metafísico de um mundo desprovido de movimento, estático, que é apreendido pela razão e explicitado por conceitos. Segundo Nietzsche, Parmênides, que não pode ser associado ao pensamento hindu (como Anaximandro e Schopenhauer), mas ao pensamento otimista moderno, pretende ter chegado à concepção de ser - o conceito "mais rígido, mais frio e menos expressivo de todos" -(FTG, 11) bem como à divisão entre ser e não-ser a partir de uma lógica conduzida 
pelo intelecto de forma irrefutável. Porém, o que ele faz é apenas colocar no mundo aquilo que observa nele mesmo. "Como se a origem empírica mais miserável não aparecesse já na etimologia da palavra [ser]! Pois 'esse', no fundo, significa apenas respirar: se o homem emprega essa palavra a respeito de todas as coisas, é porque, através de uma metáfora, quer dizer, de um processo ilógico, transfere a convicção de que ele próprio respira e vive para as outras coisas e concebe a existência delas como uma respiração segundo a analogia humana" (FTG, 11).

Para sustentar seus postulados, Parmênides efetua uma "crítica ao aparelho do conhecimento", segundo a qual os sentidos fornecem apenas ilusões e o intelecto, capaz de efetuar abstrações, é a única faculdade capaz de chegar à "verdade". Diferentemente, conforme vimos, para Nietzsche e também para Schopenhauer, as palavras e os conceitos não têm um papel constitutivo em relação ao conhecimento do mundo, por exemplo. Eles apenas servem para "balbuciar em língua estrangeira" o que se apreende por intuição. A reflexão científica e a dialética servem apenas para comunicar o que fora intuído e, mesmo assim, como um "meio miserável porque, no fundo, não passa de uma transposição metafórica e absolutamente inadequada para outra esfera e para outra linguagem" (FTG, 3). Esta compreensão da intuição, que Parmênides não possui, Nietzsche encontra em Anaximandro e também em Tales, que, conforme já mencionamos, lançou mão da água como uma metáfora para comunicar aquilo que havia intuído acerca da unidade de tudo o que existe. ${ }^{7}$

Para finalizar, diante do que foi visto e tendo presente a proposição de Zaratustra: "Retribui-se mal um mestre, quando se permanece sempre e somente discípulo," podemos afirmar que o jovem Nietzsche retribui bem ao seu mestre. Pois a ele se aplica o que afirma em relação a Schopenhauer, que teria se apropriado da filosofia de Kant como um meio de expressão, como um instrumento retórico entre mil meios possíveis para uma única tarefa (CE, III, 7). Diferentemente do que faria um mau discípulo, também Nietzsche se apropria de fórmulas da filosofia de Schopenhauer para realizar um propósito próprio e muito diferente da finalidade inerente à filosofia de seu antecessor.

Sobre este aspecto, do recurso a metáforas, Heráclito é ainda mais pródigo que os outros filósofos pré-socráticos: ao ser chamado a explicar sua filosofia, ele faz menção a Zeus, à criança, ao fogo, ao jogo e não a conceitos. Ademais, lança mão de argumentos próprios a quem não se sente obrigado a reconhecer qualquer papel criador da razão lógica. Argumentos que seriam inaceitáveis "até no domínio das idéias místicas", tais como, por exemplo, que o uno seria, enquanto um jogo, simultaneamente o múltiplo (FTG, 7). Segundo Nietzsche: "todas as palavras de Heráclito exprimem o orgulho e a majestade da verdade, mas de uma verdade que ele apreende em intuições e que não conquista na escada de corda da lógica" (FTG, 9). 
Assim, mais do que diferenças pontuais entre o pensamento de ambos - conforme vimos, facilmente identificadas e mais acentuadas nos textos inéditos - tem-se com Nietzsche um pensamento novo, cujo parentesco será muito maior com o próprio desdobramento de sua filosofia do que com um eventual precursor. Observe-se que é o seu propósito próprio que o leva a manifestar simpatia para com Heráclito, o filósofo que o convida a andar a passos leves e com certa despreocupação em relação à lógica. Mais ainda, o convida a olhar para o devir sem buscar nele resquícios de uma culpa a ser expiada. Assim, Nietzsche não tem como se manter próximo, de forma acrítica, de uma filosofia - a de Schopenhauer - que recusa o que para ele é um ponto de partida: da exteriorização da força, do vir-a-ser que constitui mundos e os empurram novamente para o nada não se pode inferir qualquer ideia de castigo ou punição: o devir é inocente.

\section{Referências}

BARANGER, W. Pour connaitre la pensée de Nietzsche. Paris: Bordas, 1945.

BENCHIMOL, M. Apolo e Dionísio: arte, filosofia e crítica da cultura no primeiro Nietzsche. São Paulo: Annablume, 2002.

CAVAlCANTI, A. H. Símbolo e alegoria: a gênese da concepção de linguagem em Nietzsche. São Paulo: Annablume, 2005.

HAAR, M. La rupture initiale avec Schopenhauer. In: Nietzsche et la métaphysique. Paris: Gallimard, 1993.

MACHADO, R. Nietzsche e a polêmica sobre o nascimento da tragédia. Rio de Janeiro: Jorge Zahar, 2005.

NIETZSCHE, F. Die Geburt der Tragödie. Unzeitgemäße Betrachtungen I - IV. Nachgelassene Schriften 1870 - 1873. Kritische Studienausgabe Herausgegeben von Giorgio Colli und Mazzino Montinari. Berlin: Walter de Gruyter, 1988.

Nachgelassene Fragmente 1869 - 1874: Kritische Studienausgabe Herausgegeben von Giorgio Colli und Mazzino Montinari. (KSA 7) Berlin: Walter de Gruyter, 1988.

O nascimento da tragédia. Tradução de J. Guinsburg. São Paulo: Companhia das Letras, 1992. 
. Considerações extemporâneas III: Schopenhauer como educador. Tradução de Rubens R. Torres Filho. São Paulo: Nova Cultural, 1991. p. 3545. (Obras incompletas, v. II).

A filosofia na idade trágica dos gregos. Tradução de Maria Inês Madeira de Andrade. Rio de Janeiro: Elfos; Lisboa: Edições 70, 1995.

Ecce homo. Tradução de Paulo César de Souza. São Paulo: Companhia das Letras, 1995.

SCHOPENHAUER, A. O mundo como vontade e como representação. Tradução de Jair Barboza. São Paulo: Editora da Unesp, 2005.

Parerga und Paralipomena II. Zürich: Haffmans Verlag, 1988.

SIMMEL, G. Schopenhauer y Nietzsche. Buenos Aires: Prometeo Libros, 2005.

Recebido: 13/03/2008

Received: 03/13/2008

Aprovado: $18 / 04 / 2008$

Approved: 04/18/2008 